https://helda.helsinki.fi

\title{
The sensitivity based estimation of leaf area index from spectral vegetation indices
}

\section{Gonsamo, Alemu}

2012

Gonsamo , A \& Pellikka, P 2012 , ' The sensitivity based estimation of leaf area index from spectral vegetation indices ' , ISPRS Journal of Photogrammetry and Remote Sensing , vol. 70 , pp. 15-25 . https://doi.org/10.1016/j.isprsjprs.2012.03.009

http://hdl.handle.net/10138/44816

https://doi.org/10.1016/j.isprsjprs.2012.03.009

publishedVersion

Downloaded from Helda, University of Helsinki institutional repository.

This is an electronic reprint of the original article.

This reprint may differ from the original in pagination and typographic detail.

Please cite the original version. 
Provided for non-commercial research and education use. Not for reproduction, distribution or commercial use.

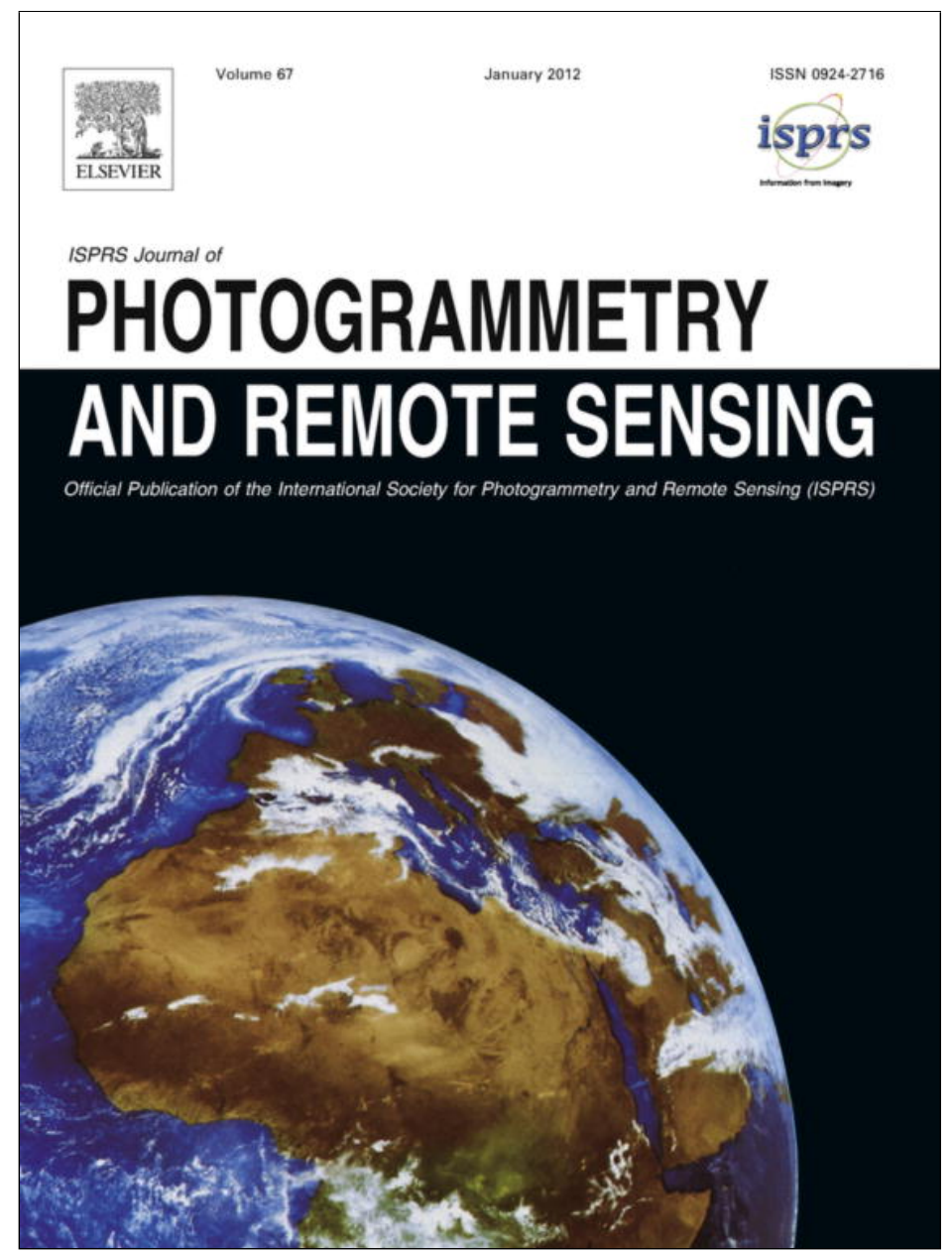

(This is a sample cover image for this issue. The actual cover is not yet available at this time.)

This article appeared in a journal published by Elsevier. The attached copy is furnished to the author for internal non-commercial research and education use, including for instruction at the authors institution and sharing with colleagues.

Other uses, including reproduction and distribution, or selling or licensing copies, or posting to personal, institutional or third party websites are prohibited.

In most cases authors are permitted to post their version of the article (e.g. in Word or Tex form) to their personal website or institutional repository. Authors requiring further information regarding Elsevier's archiving and manuscript policies are encouraged to visit:

http://www.elsevier.com/copyright 


\title{
The sensitivity based estimation of leaf area index from spectral vegetation indices
}

\author{
Alemu Gonsamo $^{\mathrm{a}, \mathrm{b}, *}$, Petri Pellikka ${ }^{\mathrm{b}}$

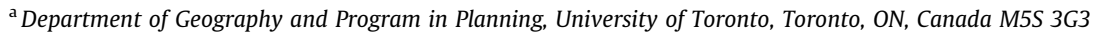 \\ ${ }^{\mathrm{b}}$ Division of Geography, Department of Geosciences and Geography, University of Helsinki, P.O. Box 64, FIN-00014 Helsinki, Finland
}

\section{A R T I C L E I N F O}

\section{Article history:}

Received 16 February 2011

Received in revised form 15 December 2011 Accepted 23 March 2012

\section{Keywords:}

Leaf area index

Sensitivity function

Spectral vegetation index

\begin{abstract}
A B S T R A C T
The performances of seven spectral vegetation indices (SVIs) were investigated for their sensitivity to a varying range of LAI. The evaluation was carried out for a dataset collected using SPOT 5 HRG $10 \mathrm{~m}$ imagery and simulated spectra using PROSPECT + SAIL reflectance models with varying soil reflectance backgrounds. The aim was to evaluate the applicability of multiple SVIs for LAI mapping based on the sensitivity analysis. The main sensitivity function was the first derivative of the regression function divided by the standard errors of the SVIs. In addition, the sensitivity of individual band and SVI with LAI was carried out using the ordinary least squares regressions. A new SVI, reduced infrared simple ratio (RISR) was developed based on an empirical red modification to infrared simple ratio (ISR) SVI. The new SVI was demonstrated which has significantly reduced the effect of soil background reflectance while maintaining high sensitivity to a wide range of LAI.

(C) 2012 International Society for Photogrammetry and Remote Sensing, Inc. (ISPRS). Published by Elsevier
\end{abstract} B.V. All rights reserved.

\section{Introduction}

Ecosystem process and biogeochemical cycling models are evidently run in a spatially explicit mode, requiring as model drivers multi-scale and multi-date biogeophysical parameters such as leaf area index (LAI), which are derived mainly from satellite imagery (Running et al., 1999). LAI is defined as one half the total leaf area per unit ground surface area projected on the local horizontal datum (Gonsamo and Pellikka, 2008). Estimation of continuous variables like LAI from high-resolution imagery such as SPOT or Landsat satellite series has largely depended on developing empirical relationships derived from a single spectral vegetation index (SVI) based on red and near-infrared (NIR) reflectance (Cohen et al., 2003). SVIs are important but utilize only a fraction of the spectral information available in many spectral bands. Cohen et al. (2003) demonstrated an improved strategy for mapping LAI using SVIs derived from multiple dates. The use of multiple date optical remote sensing is often limited by the lack of appropriate multitemporal observations. The cost of the existing satellite imagery such as SPOT High Resolution Geometric (HRG) is considerably high making multiple date imagery difficult to use. Moreover, multiple date relationships are hampered by specific SVI-LAI relationships which may only be appropriate for the time during which they were generated at a given phenological state of the plants.

\footnotetext{
* Corrresponding author at: Department of Geography and Program in Planning, University of Toronto, Toronto, ON, Canada M5S 3G3. Tel.: +1 416946 7715; fax: +1 4169463886.

E-mail address: gonsamoa@geog.utoronto.ca (A. Gonsamo).
}

Empirical models are easy to use and important tools for relating field measured LAI to remote sensing data. Regression analysis has been a popular empirical method of linking field measured biogeophysical parameters to remote sensing data to provide continuous estimates for variables such as biomass, percent woody canopy cover, and LAI. Traditional methods of regression result in insufficient accuracy when resulting biogeophysical surfaces derived from remote sensing are subsequently used for ecosystem process models (Cohen et al., 2003). To this regard, a large number of SVIs have been developed and used in remote sensing. This indicates the compelling reasons for utilizing greater spectral dimensionality, and for including multiple SVIs from multiple spectral bands in a regression analysis.

High reflectance and transmittance of leaves particularly broadleaves in the NIR spectral regions can cause strong multiple scattering. This multiple scattering increases rapidly as LAI increases from zero. In such cases, the reflectance in one or several directions can be insensitive to various parameter values, e.g., LAI. Therefore, SVIs are known to saturate at fairly low LAI values of about 2-3 (Chen et al., 2002). This saturation effect limits the usefulness of optical remote sensing for biogeophysical parameter mapping for mature forests as their LAI values are generally larger than 2 , even in the boreal environment and temperate broadleaved forests. In such cases, more information must be provided to the algorithm to localize the solution. To this effect, some studies have employed sensitivity analysis of SVI to LAI as a function of LAI, e.g., Baret and Guyot (1991) developed the relative equivalent noise (REN); Huete et al. (1994) employed the vegetation equivalent noise (VEN) to represent noise in SVI; Becker and Choudhury (1988) developed the relative 
sensitivity $(R)$ based on the regression function of two rescaled SVIs; Gitelson (2004) proposed another relative sensitivity; and more recently Ji and Peters (2007) demonstrated new sensitivity function. The sensitivity function as a function of biogeophysical parameters are required at each observation because the goodness-of-fit measures such as the coefficient of determination $\left(R^{2}\right)$ and root mean squared error (RMSE) are only useful for indicating the general sensitivity of the SVI. The $R^{2}$ of a non-linear regression model, commonly called pseudo- $R^{2}$, can not be interpreted as the proportion of variability explained by the model and can vary greatly from each other within the same model (Schabenberger and Pierce, 2002). The sensitivity of an SVI to a biogeophysical parameter is not a constant value, but is a function of the biogeophysical parameter. However, to this date, there is no convergence of methods aiming at mapping LAI based on the sensitivity functions. These and the saturation problems associated with SVI-LAI relationships require a cascade of methodologies to be developed in order to formulate robust approaches. Several statistical approaches have been appeared in literature although they are rarely exploited in the remote sensing domain. Therefore, the objectives of this study are: (i) assessment of the variability in SVI-LAI relationships across LAI ranges using sensitivity function and goodness-of-fit tests, and (ii) development of a method for selecting appropriate multiple SVIs for retrieving LAI from remote sensing data based on the theoretical and best-fit SVI-LAI relationships.

\section{Methodology}

\subsection{Study area}

The study site is located in the Great Lakes - St. Lawrence forest in Southern Quebec, Canada. It is part of the Gatineau Park, which is managed by the National Capital Commission (NCC) of Canada and centered at $45^{\circ} 30 \mathrm{~N}, 75^{\circ} 52$ W. The park is about $10 \mathrm{~km}$ by $50 \mathrm{~km}$ and is mostly temperate hardwood forest with a dominant overstory of sugar maple (Acer saccharum Marsh.) and small patches dominated by American beech (Fagus grandifolia Ehrh.), trembling aspen (Populus tremuloides Michx.), and red oak (Quercus rubra L.). Small numbers of red maple (Acer rubrum L.), American basswood (Tilia americana L.), ironwood (Ostrya virginiana (Mill.) K. Koch), white ash (Fraxinus americana L.), black ash (Fraxinus nigra Marsh.), white birch (Betula papyrifera Marsh.), and black cherry (Prunus serotina Ehrh.) are also present. The study plots were located in the southern portion of the park (Fig. 1). They have been part of long-term research on monitoring forest damage, structure, health and succession following the ice storm of 1998 (Pellikka et al., 2000; Gonsamo et al., 2011).

\subsection{Ground-based LAI measurements}

We established $20 \mathrm{~m}$ by $20 \mathrm{~m}$ plots in the Gatineau Park (number of plots, $n=61$ ) along two north-south oriented transects (Fig. 1). Both transects were established in 1998 and were sites of previous studies for the ice storm damage (Pellikka et al., 2000 ). A subset ( $n=54$ ) of previously inventoried forest plots that could be easily found in 2007 were selected for LAI measurements. Plot corners were surveyed using differential Global Positioning System (GPS) to provide positional accuracy on the order of $<1 \mathrm{~m}$.

The ground LAI measurements were collected using digital hemispherical photography during the peak of the growing season between August 10th and 20th, 2007. The photographs were acquired using a high resolution (8 mega pixels) Nikon Coolpix 8800 VR digital camera equipped with a fish-eye Nikon FC-E9 lens adapter (Nikon Inc., Japan). In total, five photographs were acquired in each study plot, one at each corner and one at the center. All pho- tographic procedures are described in Gonsamo et al. (2011). LAI was computed for the range of $0-60^{\circ}$ view zenith angle to reduce the growing effects of mixed pixels near the horizon, which result from light scattering and coarse resolution. All photographs were analysed using CAN_EYE software (http://www.avignon.inra.fr/ can_eye). Note: for simplicity, the effective LAI, which assumes random foliage distribution, was used in this study and is hereafter referred to as LAI. Ground-based LAI ranged from 2.6 to 5.7 along the two sampling transects of Gatineau Park. The LAI distribution was close to normal and was centered at around 4 (Fig. 2).

\subsection{Remote sensing data}

Radiances in digital counts in the green $(500-590 \mathrm{~nm})$, red (610-680 nm), near-infrared (NIR) $(780-890 \mathrm{~nm})$ and shortwaveinfrared (SWIR) (1580-1750 nm) wavelength regions were obtained in $10 \mathrm{~m}$ resolution acquired on the cloud free day of July 23, 2007, by the SPOT 5 HRG instrument for $60 \times 60 \mathrm{~km}$ image swath. The sun zenith and azimuth angles were 30 and 140 degrees, respectively. The view zenith angle was 20 degrees. The image was orthorectified using a three arc seconds digital elevation model (DEM) obtained from Canadian Digital Elevation Data (CDED) (http://www.geobase.ca). The source digital data for CDED at scales of 1:50,000 were extracted from the hypsographic and hydrographic elements of the National Topographic Data Base and various scaled positional data acquired from the provinces and territories. The geometric correction model was based on the SPOT XS sensor collinearity equations. The SPOT image was registered using 139 ground control points from orthorectified digital aerial photography and national road network of Canada (http:// www.geobase.ca) into UTM zone 18 with a NAD83 datum. The $X$ and $Y$ root mean square errors were below $6 \mathrm{~m}$ ( 0.6 pixels).

We used radiative transfer code developed by Vermote et al. (1997) called 6S (second simulation of the satellite signal in the solar spectrum). $6 \mathrm{~S}$ first produces three atmospheric correction coefficients called $a, b$, and $c$. Atmospherically corrected reflectance (acr) is then obtained from the measured at satellite radiance in $\mathrm{W} \mathrm{m} \mathrm{m}^{-2} \mathrm{sr}^{-1} \mu \mathrm{m}^{-1}$ (Lsat ${ }_{\lambda}$ ) for band $\lambda$ using the following formulae: acr $=\frac{y}{1+c y}$

where $y=\mathrm{aLsat}_{\lambda}-\mathrm{b}$.

We used a standard middle latitude summer atmospheric model proposed by $6 \mathrm{~S}$ code. This was due to the fact that the atmospheric characteristics data were not available for the time of satellite overpass and the effect of the atmospheric correction from a standard atmospheric model is usually comparable to that obtained from an in-situ model. We also used a standard aerosol model (the continental aerosols model) to define aerosol type. The AERONET aerosol optical depth (AOD) data was integrated with spatio-temporal constraints that the SPOT scene is located to two nearest AERONET sites and the measured AOD is computed from the closest satellite overpass time. AOD at $550 \mathrm{~nm}$ was then interpolated from AOD $440 \mathrm{~nm}$ and Angstrom exponent $\alpha(440-675 \mathrm{~nm})$ :

$$
\operatorname{AOD}(550 \mathrm{~nm})=\frac{\operatorname{AOD}(440 \mathrm{~nm})}{\left[\frac{550 \mathrm{~nm}}{440 \mathrm{~nm}}\right]^{\alpha(440-675)}}
$$

\subsection{Radiative transfer model simulation at the leaf and canopy levels} with measured soil background data

The combined PROSPECT leaf optical properties model (Jacquemoud and Baret, 1990) and SAIL turbid medium canopy bidirectional reflectance model (Verhoef, 1984), also referred to as PROSAIL, were used in order to evaluate the spectral sensitivity of SVIs to LAI. The canopy reflectance was simulated at $1 \mathrm{~nm}$ 


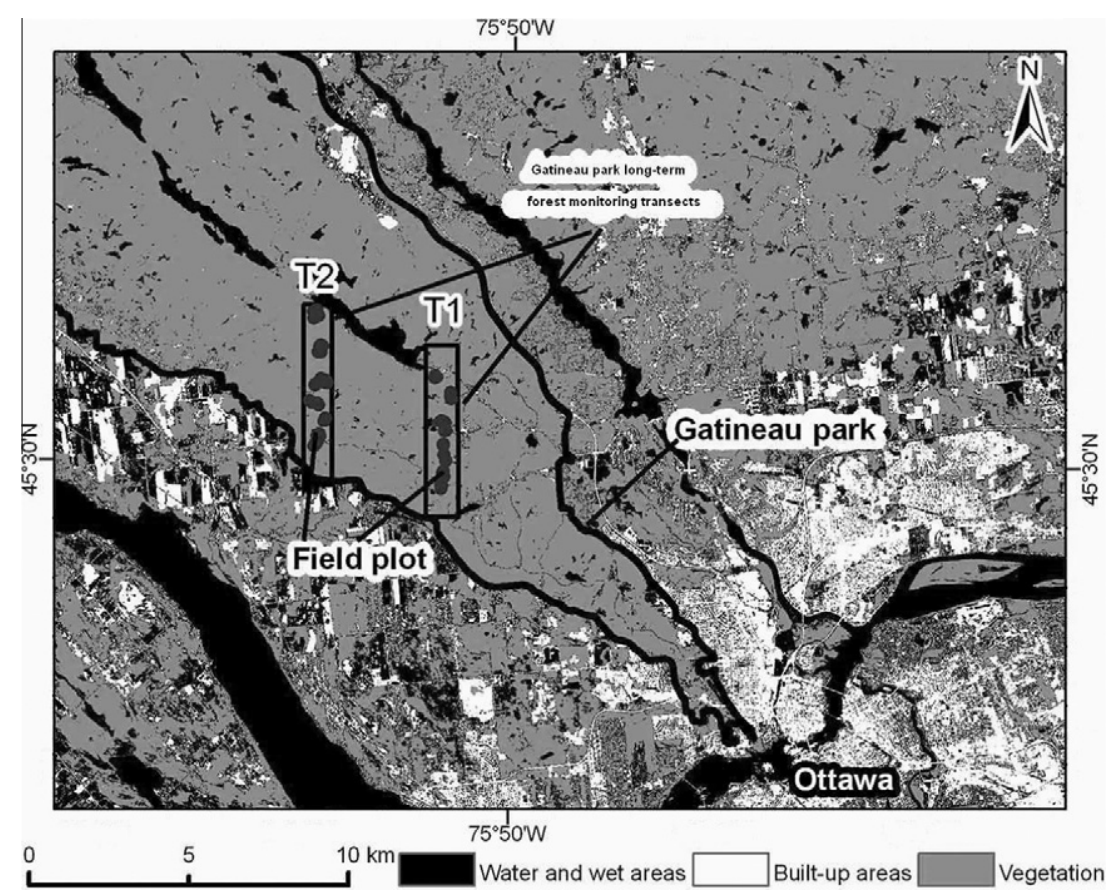

Fig. 1. Location of study area with the general land cover map derived from the same SPOT HRG image used in this study showing the southern portion of Gatineau Park, long-term forest monitoring transects, and field plot locations.

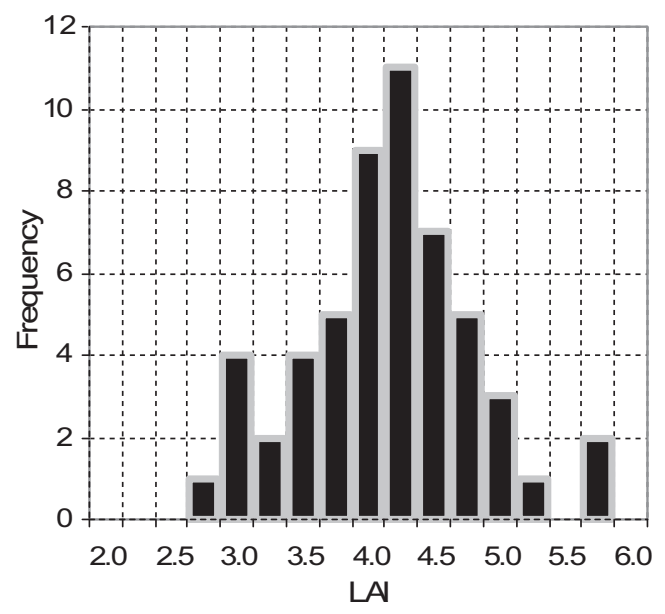

Fig. 2. Frequency distribution of LAI at Gatineau Park.

intervals for a range of plausible input parameters and convolved with the spectral response functions of the three bands of SPOT corresponding to red, NIR and SWIR. PROSPECT uses the following input parameters: chlorophyll $a$ and $b$ content $\left(C_{\mathrm{ab}}, \mu \mathrm{g} \mathrm{cm}^{-2}\right)$, dry biomass content $\left(C_{\mathrm{m}}, \mathrm{g} \mathrm{cm}^{-2}\right)$, equivalent leaf water content $\left(C_{\mathrm{w}}, \mathrm{g} \mathrm{cm}^{-2}\right)$, and mesophyll structure parameter $(N)$; and SAIL uses: LAI, leaf angle distribution (LAD), soil reflectance $\left(R_{\mathrm{s}}\right)$ and external parameters like view, Sun zenith $\left(\theta_{\mathrm{v}}, \theta_{\mathrm{s}}\right)$ and azimuth $\left(\varphi_{\mathrm{v}}, \varphi_{\mathrm{s}}\right)$ angles. For this analysis, the ranges of the LAI inputs were $0.25-9$ by increment of 0.25 , and 12 , the latter to represent the largest LAI value. Three different soil backgrounds ranging from dark to bright were specified from Bowker et al. (1985) and were used to evaluate the sensitivity of SVI-LAI relationships for varying soil spectra. The other input parameters were kept constant: $N=1.55, C_{\mathrm{ab}}=34.24, C_{\mathrm{w}}=0.0137, C_{\mathrm{m}}=0.0045$, spherical leaf angle distribution (LAD), $\theta_{\mathrm{v}}=0^{\circ}, \theta_{\mathrm{s}}=30^{\circ}, \varphi_{\mathrm{v}}=0^{\circ}$, and $\varphi_{\mathrm{s}}=0^{\circ}$. Since we evaluate a newly developed SVI for LAI mapping, and the other SVIs considered here are developed from broadband spectra for vegetation structural parameter retrieval, we have restricted all biochemical inputs to constant values. Therefore, all the sensitivity analysis in this study focuses on the SVI sensitivity along the LAI gradients on various background reflectance conditions.

\subsection{Spectral vegetation indices (SVIs)}

We calculated seven SVIs from the surface reflectance using the red (XS2), near-infrared (XS3), and short-wave infrared (XS4) SPOT HRG bands and simulated datasets. The formulae for these indices are illustrated in Table 1 . We selected SVIs based on the extensive use, performance and sensitivity to LAI on high vegetation cover. The other criterion was the sensitivity of the SVIs to the effect of undergrowth. Ratio based SVIs are often preferred to others, such as soil based indices, as the soil spectral characteristics needed to establish the soil line are often unavailable or are influenced by soil variability. Maximum and minimum of band XS2 and XS4 were computed from forest and open areas, but no water or wet areas for the SPOT data. For simulated data, maximum and minimum of red and SWIR bands were obtained from largest LAI $(=12)$ and soil spectra, respectively for each soil background separately.

As shown in Fig. 3, all SVIs considered in this study are assumed to contain additional information. Except the paired relationships of NDVI-SR and NDII-ISR, there are considerable differences of all SVIs computed for the ground plots. It has long been recognized that inclusion of a SWIR band in SVIs based on visible and NIR reflectance can provide useful complementary information on the geometrical structure of the canopy, on the optical properties of the underlying soil and to adjust canopy closure and background reflectance in the retrieval of LAI (Baret et al., 1988; Brown et al., 2000). To this end, ISR is extended by correcting by scaled difference of red reflectance and named reduced infrared simple ratio (RISR). The new vegetation index, RISR, is assumed to reduce the soil background effect. 
Table 1

Summary of seven ratio based spectral vegetation indices used in this analysis.

\begin{tabular}{|c|c|c|c|}
\hline Index & Algorithm & Name & Reference \\
\hline SR & $\frac{X S 3}{X S 2}$ & Simple ratio & Jordan (1969) \\
\hline ISR & $\frac{X S 3}{X S 4}$ & Infrared simple ratio & Fernandes et al. (2003) \\
\hline NDVI & $\frac{X S 3-X S 2}{X S 3+X S 2}$ & Normalized difference vegetation index & Rouse et al. (1974) \\
\hline NDII & $\frac{X S 3-X S 4}{X S 3+X S 4}$ & Normalized difference infrared index & Hardisky et al. (1983) \\
\hline RSR & $\frac{X S 3}{X S 2} \frac{X S 4 \max -X S 4}{X S 4 \max -X S 4 \min }$ & Reduced simple ratio & Brown et al. (2000) \\
\hline RNDVI & $\frac{X S 3-X S 2}{X S 3+X S 2} \frac{X S 4 \max -X S 4}{X S 4 \max -X S 4 \min }$ & Reduced normalized difference vegetation Index & Nemani et al. (1993) \\
\hline RISR & $\frac{X S 3}{X S 4} \frac{X S 2 \max -X S 2}{X S 2 \max -X S 2 \min }$ & Reduced infrared simple ratio & This study \\
\hline
\end{tabular}

$\mathrm{XS} 2=$ red reflectance, $\mathrm{XS} 3=$ near-infrared reflectance, $\mathrm{XS} 4=$ short-wave infrared reflectance.

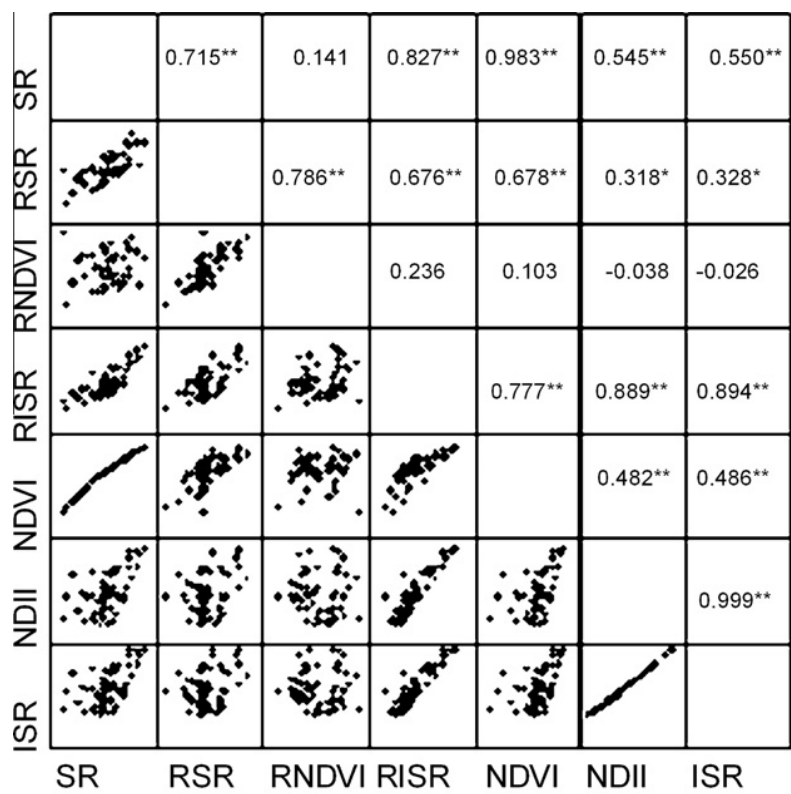

Fig. 3. Comparison of the seven SVIs from the ground plots (Pearson correlation coefficient, ${ }^{* *} p$ value is $<0.01$ and ${ }^{*} p$ value is $<0.05$ ). The formulations of the indices are given in Table 1.

\subsection{SVI-LAI sensitivity analysis}

A large amount of work has been published on the derivation of LAI and other biogeophysical parameters from optical remote sensing data. Most studies rely on empirical approaches based on the relationships or developing regression models between SVIs and LAI (e.g., Baret and Guyot, 1991; Chen et al., 2002; Cohen et al., 2003; Fernandes et al., 2003). Regression models are based on the experimental relationships between combinations of reflectances in different spectral bands and the parameter to be retrieved. The general applicability of the empirical approaches is reduced because the SVIs are affected by many factors including saturation at high forest cover, atmosphere, leaf structure, canopy geometry, vegetation developmental stage, geometry of observation, understory vegetation and soil conditions. Studies have demonstrated that different SVIs are sensitive for different range of LAI values (Becker and Choudhury, 1988; Baret and Guyot, 1991; Huete et al., 1994; Gitelson, 2004; Ji and Peters, 2007). The sensitivity of SVIs varies along the LAI gradient due to the varying responses of reflectances used to compute the SVIs as a function of forest biogeophysical parameter. For the objective of this study, which is to improve the empirical approaches for modeling LAI, we investigated the use of sensitivity function on performances of individual SVI aiming to apply multiple SVIs for LAI mapping. Nevertheless, we will compare results from an improved to those obtained using commonly used regression models.

Ji and Peters (2007) showed how to build a bivariate regression of linear and nonlinear models using LAI as a predictor or independent variable and SVI as a response or dependent variable. The regression model is expressed as:

SVII $=f(\mathrm{LAI})$

The associated estimation error in the above function (3) is represented by standard error of SV̂I indicated as $\sigma_{\text {SVI }_{i}}$ for $i$ th observation. The standard error of SV̂I, commonly known as standard error of predicted mean, is expressed as:

$$
\begin{aligned}
\sigma_{\text {SVI }_{\mathrm{i}}} & =\sqrt{\sigma^{2} X_{i}^{\prime}\left(X^{\prime} X\right)^{-1} X_{i}}, \text { for linear model, or } \\
& =\sqrt{\sigma^{2} F_{i}^{\prime}\left(F^{\prime} F\right)^{-1} F_{i}}, \text { for nonlinear model }
\end{aligned}
$$

where $\sigma^{2}$ is the mean squared error of the regression model, $X$ is the matrix of independent variables, and $X_{\mathrm{i}}$ is the $i$ th row of $X, F$ is the matrix of derivatives for approximating least squares estimations and $F_{i}$ denotes the $i$ th row of $F$ matrix. In the nonlinear model $\sigma_{\text {SVI }_{i}}$ is the standard error of $S \hat{V} I_{i}$ approximated as the estimated asymptotic standard error of the estimate (Ji and Peters, 2007). We used the SAS ${ }^{\circledR}$ System statistical package to compute $\sigma_{\text {SVVl }_{1} \text {. We }}$ applied the performance evaluation of SVI for predicting LAI 
developed by Ji and Peters (2007) by dividing the first derivative of the regression function ( $\left.S \hat{V V I}^{\prime}\right)$ by the standard errors of the SVIs $\left(\sigma_{\text {SVII }}\right)$. The first derivative of the (3) is expressed as:

$\mathrm{SVII}^{\prime}=f^{\prime}(\mathrm{LAI})=\frac{\mathrm{d}(\mathrm{SV} \mathrm{I})}{\mathrm{d}(\mathrm{LAI})}$

Therefore, the sensitivity function $(S)$ is described as:

$\mathrm{S}=\frac{\mathrm{SV} \mathrm{I}^{\prime}}{\sigma_{\mathrm{SVI}}}=\frac{\mathrm{d}(\mathrm{SVI}) / \mathrm{d}(\mathrm{LAI})}{\sigma_{\mathrm{SVI}}}$ where the $S$ of $i$ th observation $=t$,

where $t$ is Student's $t$-test statistic. The $S$ value indicates the $t$-score where the sensitivity is defined statistically significant or not as the case of Student's $t$-test statistic for a given $p$-value and degree of freedom. Large positive $S$ values represent a high positive sensitivity of SVI to LAI. All $S$ values are comparable in magnitude regardless of the SVIs range and magnitude used to compute the $S$ function.

We evaluated the sensitivity of the seven SVIs to LAI based on the expected exponential (Fig. 4) and best-fit regression models using $S$ function. It is well understood that LAI is exponentially related with fractional vegetation cover and gap fraction $\left(P_{0}\right)$ according to the theoretical Beer-Lambert law of light transmission under the forest canopy (Gower and Norman, 1991) and experimental results (Becker and Choudhury, 1988; Baret and Guyot, 1991; Huete et al., 1994; Gitelson, 2004; Ji and Peters, 2007). This is due to the capacity of canopy leaf area to absorb photosynthetically active radiation, which has an approximately exponential relationship with LAI. To this regard, we evaluated both exponential and best-fit regression models between SVIs and LAI.

Besides the $S$ function, we employed segmented and moving ordinary least squares regression models in order to assess the sensitivity of SVIs along the LAI gradient. Firstly, we applied a quantile based ordinary least square regression model for the segmented data (1-10 quantiles). Quantiles are points taken at regular intervals from the cumulative distribution function (dividing ordered data into $q$ essentially equal-sized data subsets) of measured LAI. SVIs contain only partial spectral information and the sensitivity to LAI varies to different degrees. The errors and variances are usually heterogeneous for both SVI and LAI across the gradient of different forest density or cover (Kalácska et al., 2004). Therefore, localized regression models such as quantile regressions are the best choice to address the complexity of interactions between different factors leading to data with unequal variation of one

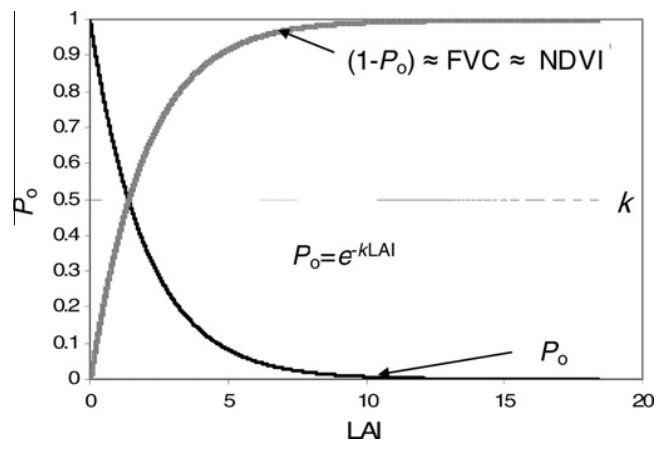

Fig. 4. Expected relationship between LAI and NDVI derived from a hypothetical data. $P_{0}$ is gap fraction, $k$ is extinction coefficient, and FVC is fractional vegetation cover. The LAI is derived from the randomly generated $P_{0}$ data ranging from $0-1$ following the inversion of the $P_{0}$ equation shown inside the figure: $\mathrm{LAI}=-\ln \left(P_{0}\right) / k$. For a broadleaved forest, $k$ typically ranges between 0.42 and 0.58 . In this figure, $k$ was assumed to be 0.5 , which is a good approximation for a broadleaved forest and was proven in the field measurement of the same study site (Gonsamo et al., 2011). Several studies have shown a complement a unit of gap fraction $\left(1-P_{0}\right)$ to be approximately equal to NDVI and FVC (e.g., Baret and Guyot, 1991; Carlson and Ripley, 1997; Gonsamo, 2010; Gonsamo et al., 2011). variable for different ranges of another variable, e.g., LAI with SVIs. Secondly, we used a moving window ordinary least squares regression model with different sizes of windows (2-20 cases/sizes of moving window) along the LAI gradient. Using the moving window and segmented regression model, we evaluated the SVI-LAI relationships based on the average correlation and the highest correlation from the best-fit SVI-LAI relationships.

\section{Results and discussion}

\subsection{SVI-LAI sensitivity from radiative transfer model simulation}

The influence of LAI and soil background on red, NIR and SWIR reflectances is shown in Fig. 5 to evaluate if the soil type variation behaves in the same manner. Red and SWIR reflectances saturate at fairly low LAI values ( $\mathrm{LAI}<4)$ where the soil background effect diminishes for these two bands. NIR reflectance shows clear soil background effect on all simulated LAI ranges while reflectance increases with increasing LAI (Fig. 5). The soil effect is consistent for the two most widely used bands for construction of SVIs, red and NIR whether the soil background is dark, intermediate or bright (Fig. 5). This is very desirable phenomenon for these two bands. SWIR reflectance on dark soil background increases with increasing LAI whereas on intermediate soil it stays more or less the same and on bright soil decreases with increasing LAI (Fig. 5). Red and NIR reflectances have strong physical bases associated with the optical thickness of photosynthetic biomass whereas SWIR reflectance is associated with the moisture content of the landscape or vegetation. And SWIR was proven to compensate for differences in canopy closure and background (mainly undergrowth effect) reflectance if included in SVI for LAI mapping (Brown et al., 2000). Except that of SWIR reflectance on dark and intermediate soil backgrounds, the results shown in Fig. 5 are in good agreement with Brown et al. (2000) where they have demonstrated the sensitivity of the three bands for LAI and background effect using 4-scale reflectance model. The results of SWIR reflectance on the dark and intermediate soil background in Fig. 5 imply

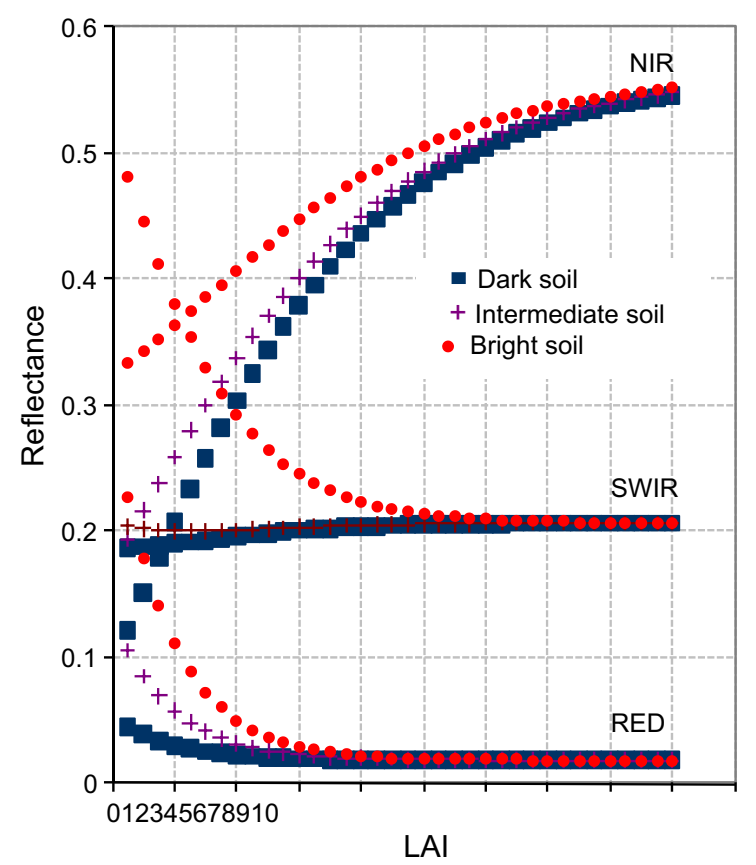

Fig. 5. Relationships between LAI and reflectances in three bands simulated for three soil background types. 
that the soil has more moisture than the canopy. This can also be noticed from the negative NDII values in Fig. 6.

As the major aim of this study was to evaluate the usability of multiple SVIs for mapping LAI, we first evaluated how sensitive the selected indices are towards the confounding effects of varying soil backgrounds and LAI ranges. Fig. 6 illustrates the effect of soil background reflectance on the SVIs and their sensitivity to the LAI. Considering both soil effect reduction and sensitivity to LAI, the newly formulated index (RISR) outperformed all the other indices (Fig. 6). Both the unreduced normalized difference indices (NDVI and NDII) show high sensitivity to low LAI $(<2)$ after which they tend to have asymptotic response to increasing LAI. Most of the SVIs (RISR, NDVI, NDII, and ISR) fit the curvilinear relationships with LAI for all soil types which can be approximated with exponential relationships (see Fig. 4). Despite the commonly perceived LAI-SR exponential relationships, Fig. 6 shows that LAI has sigmoidal relationship to SR and in good agreement with Fernandes et al. (2003).

The effect of the soil is not statistically significant for mean differences (2-tailed test, $p=0.05$ ) except for the LAI values obtained from dark and intermediate soil background from RSR and RNDVI compared with bright soil background LAI values (Fig. 6). The corrections (reduction) on simple ratio and normalized difference vegetation index using SWIR band which resulted in RSR and RNDVI, respectively, have not reduced the inconsistent soil background reflectance effects demonstrated in Fig. 5. The soil reflectance may not vary as shown in simulated spectra in the natural environment, nevertheless, using the three bands ratio indices as demonstrated in Fernandes et al. (2003) and Brown et al. (2000) proven to be not helpful. The new index (RISR) uses the advantage of the three bands while reducing the effect of soil and maintaining high sensitivity to LAI (Fig. 6). RISR can thus be used as an important photosynthetic biomass indicator particularly in irrigated crops where soil moisture variation can be cumbersome.

A more detailed quantification of relationships between SVIs and LAI are obtained using a sensitivity function $(S)$. In Table 2 and Fig. 7, the $S$ and parameter estimates are presented which are computed for calibration dataset for both exponential and best-fit models after randomly selecting half of simulated data with the three soil background types. The remaining half is set aside for application of LAI mapping using best performing SVIs. From Psuedo- $R^{2}$ of exponential and best-fit models, RSR and RNDVI once again confirmed to be poor estimators of LAI, provided that the soil background has considerable optical variations. This is in good agreement with the results shown in Figs. 5 and 6. The value of $\sigma$ (root mean square error (RMSE)) which is only comparable between the same SVIs, shows that the best-fit model is better than the expected exponential model (Table 2 ).

Among the seven SVIs, SR has the highest sensitivity for all LAI ranges from the exponential model and when LAI is greater than 3.75 from the best-fit model. The new index, RISR has the highest sensitivity when LAI is less than 3.75 from the best-fit model and statistically significant sensitivity for all ranges of LAI from the exponential model (Fig. 7). Both the exponential and best-fit sensitivity curves show that the sensitivity of SVIs decreases with LAI at an exponentially decaying rate. When $S$ is less than 2.01 (essentially the same value with critical value in two-tailed $t$-test where $p=0.05$ and degree of freedom $=48$ ), the SVIs are deemed to be not sensitive to LAI. The trend of the sensitivity is very similar for both exponential and best-fit models when LAI is greater than 3.75 . From the exponential model, SR, RISR, and NDII are statistically significant for the entire range of LAI whereas RSR and RNDVI up to 2.75, NDVI up to 5.75 and ISR up to 7.5. From the best-fit model, SR and NDII are statistically significant for entire range of LAI whereas RNDVI is not significant at all, RSR up to 3.5, NDVI up to 4.25 , and IRS up to 6.5. Subsequently, we applied the best performing SVIs functions from both exponential and best-fit models for LAI mapping on the validation dataset.

Fig. 8 presents the results of applied LAI mapping using SR from exponential model using RISR for LAI $\leqslant 3.5$ and SR for the remaining LAI values from best-fit models. The results indicated that the correlations between the true and the estimated LAI are strong. Best-fit model resulted in relatively better correlation (Fig. 8). Both models gave good results with average error of less than $10 \%$ indicating that such kind of LAI mapping using the $S$ sensitivity function is feasible.

\subsection{SVI-LAI sensitivity from measured remote sensing and ground LAI data}

As in the case of simulated dataset, we first evaluated the relationships between the three bands of SPOT HRG reflectances and the measured LAI (Fig. 9). There were no correlations between LAI vs. XS2 and LAI vs. XS3. XS4 has shown weak but statistically significant correlation with LAI $(p<0.05)$. The predictive ability of these relations is limited to LAI mapping because of the signal saturation for higher LAI values. Both the ground-based measurements and the SPOT image were acquired from the peak of the growing season in which all the ground-based LAI values (Fig. 2) are above the commonly reported saturation level (e.g., optical remote sensing signals saturate at LAI values of 2-3 in Canadian mature deciduous forests, Chen et al., 2002).

Table 3 presets the detailed parameter estimates for both the exponential and the best-fit models from the real datasets. From Psuedo- $R^{2}$ of exponential and best-fit models, RSR and RNDVI were once again confirmed to be poor estimators of LAI. This is in good agreement with the results shown in Figs. 5-7 from the simulated spectra. The value of $\sigma$ shows that once again the best-fit model is better than the expected exponential model (Table 3 ).

Fig. 10 shows the sensitivity analysis between SVIs and LAI using exponential and best-fit models given in Table 3. The SVILAI sensitivity analysis based on the $S$ function revealed that there is a strong sensitivity of SVIs to LAI, particularly using the exponential model. Using the exponential model, ISR performed best while NDVI and NDII gave comparable results (Fig. 10 (a)). All the SVIs were found to be statistically sensitive to LAI using the exponential model while the sensitivity decayed with exponential rate with increasing LAI (Fig. 10 (a)). For both exponential and best-fit models, when $S$ is greater than 2.0057 (essentially the same value with critical value in two-tailed $t$-test where $p=0.05$ and degree of freedom $=53$ ), the SVIs are deemed to be sensitive to LAI or visa versa otherwise. In this study, all the SVIs are positively correlated with LAI.

From the best-fit model, SR and RSR did not show any sensitivity to the entire range of LAI even though smaller RMSE was obtained compared to exponential model. This might explain why the sensitivity assessment using the $S$ function is not necessarily comparable with the overall fitness obtained with regression analysis. We applied the best performing SVIs for LAI mapping based on ISR for the entire LAI range using the exponential model and NDVI for LAI up to 5.13 were $S$ function has shown significant sensitivity using best-fit model (Table 3 and Fig. 10). When the LAI measured was compared with LAI predicted using both models, it did not show statistically significant correlation $(p>0.05)$. This explains that although the $S$ function gave statistically significant sensitivity, it does not hold true to apply for LAI mapping for the real dataset used in this study as opposed to the simulated dataset demonstrated in Section 3.1.

There are several possible reasons for poor performance of the $S$ function on the real dataset. The ground measurements lack the large dynamic range of LAI required for such kind of sensitivity analysis. As most of the ground LAI values are already in the 

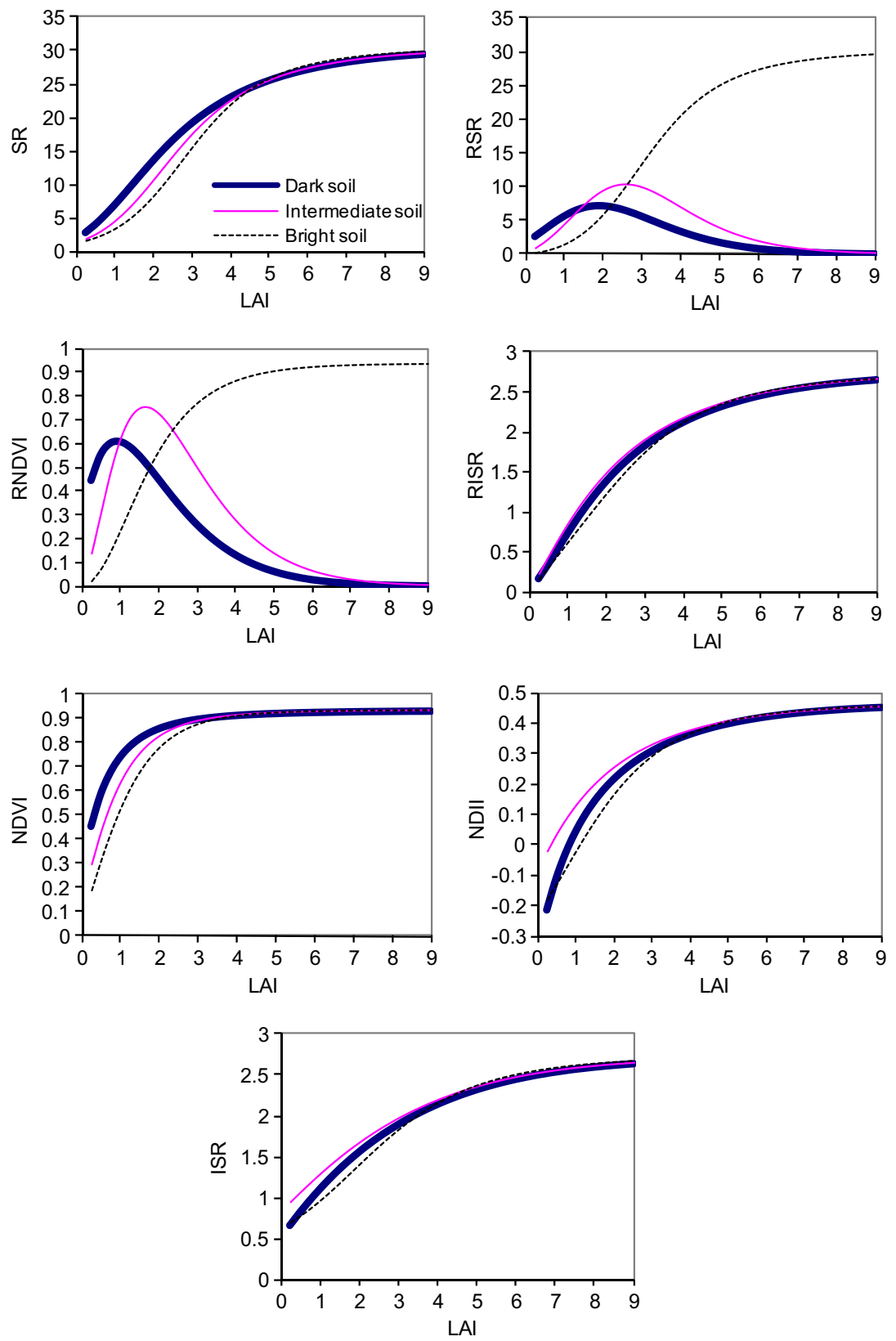

Fig. 6. Simulated results of the effect of different soil backgrounds and LAI ranges on the SR, RSR, RNDVI, RISR, NDVI, NDII, and ISR. The formulations of the indices are given in Table 1.

Table 2

The parameter estimate of exponential and best-models of calibration simulated spectra.

\begin{tabular}{|c|c|c|c|c|c|c|c|c|}
\hline \multirow[t]{2}{*}{ SVI } & \multicolumn{4}{|c|}{ Exponential model SVI = $b 1 \ln (\mathrm{LAI})$} & \multicolumn{4}{|l|}{ Best-fit model } \\
\hline & $b 1$ & $\sigma$ & $P>F$ & Pseudo- $R^{2}$ & Model & $\sigma$ & $P>F$ & Pseudo- $R^{2}$ \\
\hline SR & 14.61 & 2.74 & $<0.0001$ & 0.988 & $5.278+11.689 \ln (\mathrm{LAI})$ & 1.713 & $<0.0001$ & 0.956 \\
\hline RSR & 6.10 & 11.22 & $<0.0001$ & 0.452 & $7.0016 e^{0.0659 \mathrm{LAI}}$ & 11.176 & $<0.0001$ & 0.024 \\
\hline RNDVI & 0.22 & 0.44 & $<0.0001$ & 0.410 & $0.59 e^{-0.0637 \mathrm{LAI}}$ & 0.378 & $<0.0001$ & 0.034 \\
\hline RISR & 1.34 & 0.36 & $<0.0001$ & 0.974 & $0.866+0.86 \ln (\mathrm{LAI})$ & 0.089 & $<0.0001$ & 0.977 \\
\hline NDVI & 0.51 & 0.29 & $<0.0001$ & 0.896 & $0.707+0.1215 \ln (\mathrm{LAI})$ & 0.045 & $<0.0001$ & 0.769 \\
\hline NDII & 0.23 & 0.05 & $<0.0001$ & 0.980 & $0.1189+0.163 \ln (\mathrm{LAI})$ & 0.026 & $<0.0001$ & 0.949 \\
\hline ISR & 1.35 & 0.50 & $<0.0001$ & 0.954 & $1.1999+0.683 \ln (\mathrm{LAI})$ & 0.092 & $<0.0001$ & 0.962 \\
\hline
\end{tabular}

$\sigma=$ root mean square error (RMSE). The formulations of the indices are given in Table 1.

saturation domain of the optical remote sensing data, the combined influence of any possible errors such as atmospheric interference, tree self shadowing, and plant clumping, to mention few, may be larger than the reflectance response at such high LAI values. The 

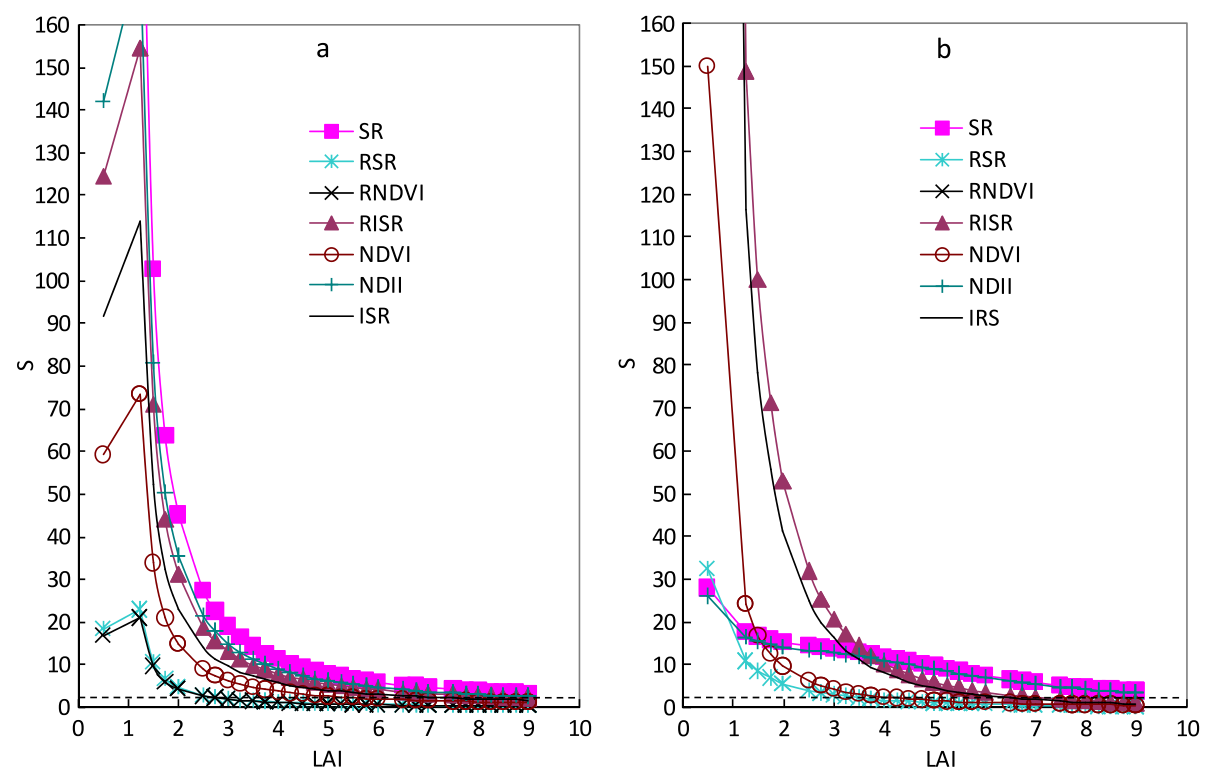

Fig. 7. Sensitivity analysis using $S$ function for the seven spectral vegetation indices and simulated true LAI from calibration dataset of simulated spectra. (a) Sensitivity function $(S)$ for the exponential, and (b) the best-fit models. The sensitivity of a spectral vegetation index to LAI is significant when $S>2.01$. The formulations of the indices are given in Table 1.

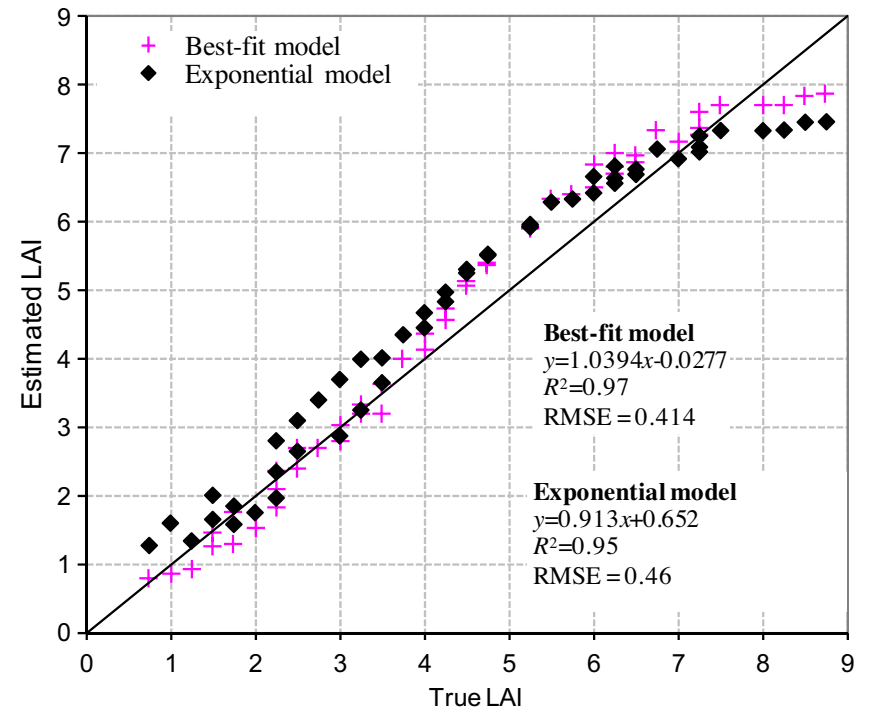

Fig. 8. Estimated LAI vs. true LAI using validation dataset of simulated spectra.

ground-based LAI is measured at $1.3 \mathrm{~m}$ above ground level as such the understory vegetation below that will not be included in the measured LAI. Whereas, the remote sensing data is acquired topdown for which both the visible understory and overstory contribute to the measured reflectance. The aforementioned reasons also explain the diverging sensitivity results of the real and simulated data. The simulated data is not affected as such by various external factors discussed above as real data. Therefore, further study is needed to test the applicability of the sensitivity based LAI estimation from multiple SVIs and the new SVI (RISR).

We further analysed the SVI-LAI relationships based on the localized classical regression in order to evaluate the results obtained from the $S$ function with the real data. Fig. 11 (a) and (b) show the $R^{2}$ obtained for each segments after dividing the data into 10 quantiles and the average $R^{2}$ for varying quantile divisions, respectively. The result indicates that the sensitivity using classical

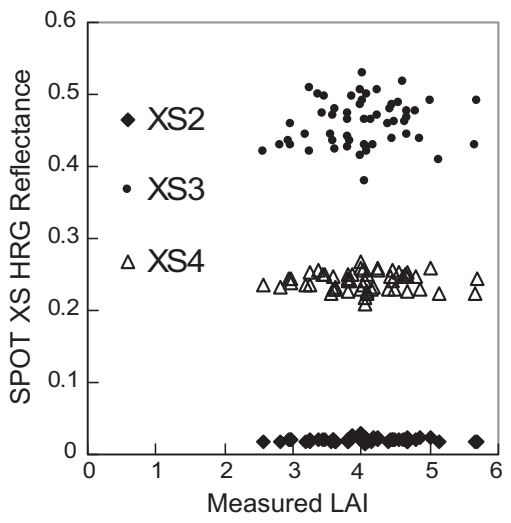

Fig. 9. The relationships between ground-based LAI and the three spectral bands of SPOT HRG. XS2 = red reflectance, XS3 = near-infrared reflectance, XS4 = short-wave infrared reflectance.

regression for data sets divided into 10 subsets is considerably different than what was obtained using the $S$ function (Fig. 11 (a)). Fig. 11 (a) shows very low $R^{2}$ for the data segments around four which is the mean value of the ground based LAI measurements where most of the ground-based values occur (Fig. 2). In both Fig. 11 (a) and (b), RSR and RNDVI which performed poorly for both simulated and the real data using $S$ function have shown relatively good correlation using the segmented regression analysis. In Fig. 11 (b) and (c), the ' 1 ' number of quantiles on $X$ axis shows the $R^{2}$ of the entire dataset.

When the number of quantile divisions increases, both the average and the maximum $R^{2}$ of each SVI and best performing SVIs, respectively increase (Fig. 11 (a) and (b)). The moving window analysis also shows the increase of $R^{2}$ when the amounts of data points are decreased (Fig. 11 (d)). In both Fig. 11 (c) and (d), the criteria used for best performing SVI selection included the $R^{2}$ and the $p$-value for individual model terms. Generally speaking, both segmented and moving average regressions show how sensitive the SVIs are at varying ranges of LAI using linear correlation term. However, the results are very specific for this dataset due to the 
Table 3

The parameter estimate of exponential and best-fit models of real data.

\begin{tabular}{|c|c|c|c|c|c|c|c|c|}
\hline \multirow[t]{2}{*}{ SVI } & \multicolumn{4}{|c|}{ Exponential model SVI = $b 1 \ln (\mathrm{LAI})$} & \multicolumn{4}{|l|}{ Best-fit model } \\
\hline & $b 1$ & $\sigma$ & $P>F$ & Pseudo- $R^{2}$ & Model & $\sigma$ & $P>F$ & Pseudo- $R^{2}$ \\
\hline SR & 16.68 & 3.784 & $<0.0001$ & 0.974 & $11.34\left(1+e^{0.01 \mathrm{LAI}}\right)$ & 2.625 & $<0.0001$ & 0.001 \\
\hline RSR & 5.61 & 1.637 & $<0.0001$ & 0.959 & $3.83\left(1+e^{0.01 \mathrm{LAI}}\right)$ & 1.350 & $<0.0001$ & 0.000 \\
\hline RNDVI & 0.22 & 0.054 & $<0.0001$ & 0.971 & $0.315\left(1-e^{-\mathrm{LAI}}\right)$ & 0.038 & $<0.0001$ & 0.000 \\
\hline RISR & 1.16 & 0.199 & $<0.0001$ & 0.985 & $1.5312 e^{0.014 \mathrm{LAI}}$ & 0.084 & $<0.0001$ & 0.028 \\
\hline NDVI & 0.66 & 0.111 & $<0.0001$ & 0.986 & $0.937\left(1-e^{-\mathrm{LAI}}\right)$ & 0.017 & $<0.0001$ & 0.017 \\
\hline NDII & 0.22 & 0.038 & $<0.0001$ & 0.986 & $0.29 e^{0.02 \mathrm{LAI}}$ & 0.000 & $<0.0001$ & 0.057 \\
\hline ISR & 1.37 & 0.225 & $<0.0001$ & 0.986 & $1.8 e^{0.02 \mathrm{LAI}}$ & 0.084 & $<0.0001$ & 0.057 \\
\hline
\end{tabular}

$\sigma=$ root mean square error (RMSE). The formulations of the indices are given in Table 1 .
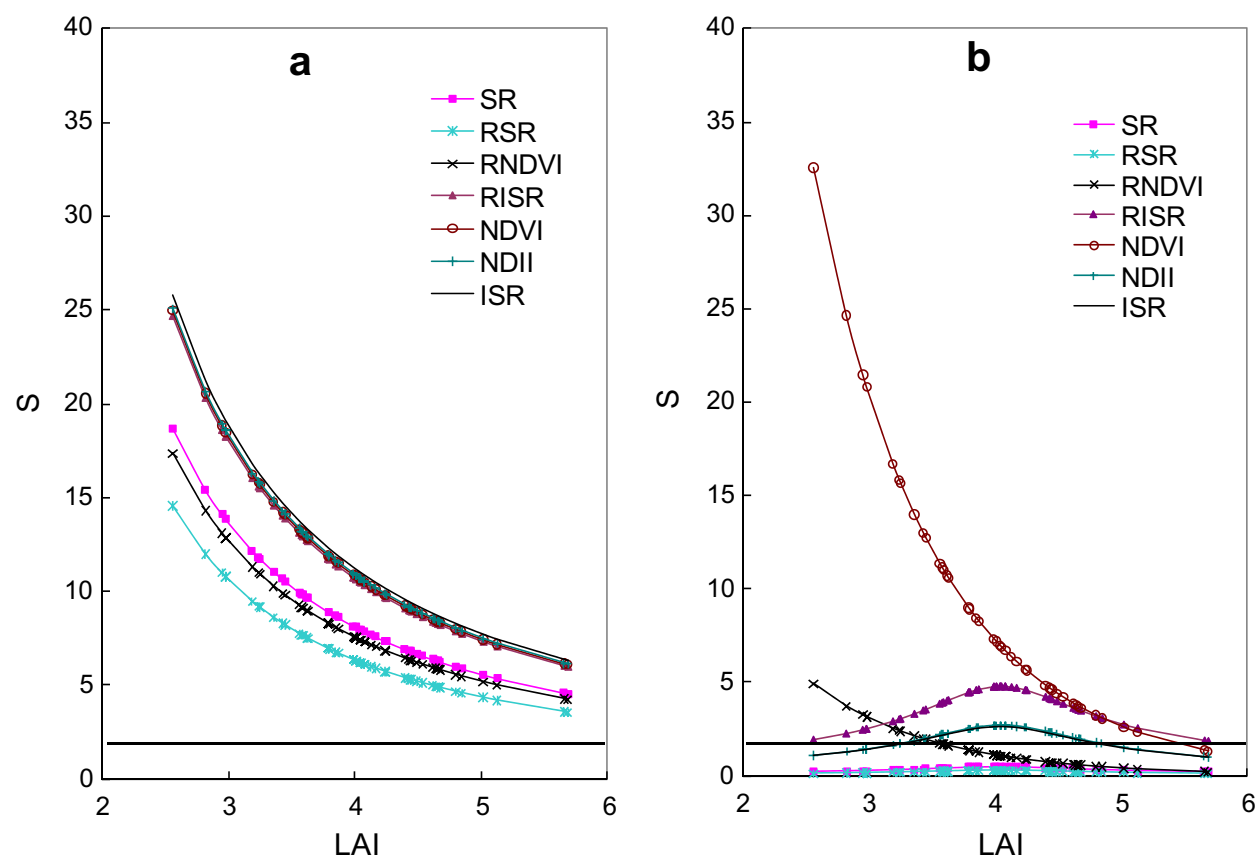

Fig. 10. Sensitivity analysis using $S$ function for the seven spectral vegetation indices and measured LAI. (a) Sensitivity function $(S)$ for the exponential, and (b) the best-fit model. The sensitivity of a spectral vegetation index to LAI is significant when $S>2.0057$ (the horizontal black line). The formulations of the indices are given in Table 1 .

limited range of the ground based LAI measurements although they are normally distributed (Fig. 2).

By and large, there are compelling reasons to use several SVIs for LAI mapping for various ranges of photosynthetic biomass density and fractional vegetation cover. For example, Carlson and Ripley (1997) and Verstraete and Pinty (1991) described that the variation of NDVI with respect to the LAI in partially vegetated areas would be mostly controlled by the variation in the fraction of vegetated surface area illuminated by the sun and visible to the radiometer than by changes in the optical thickness of canopies. The decrease of NIR at low LAI is usually attributed to an increase in the probability of observing shadowed background. At low LAI and nadir view, tree shadows tend to fall on the background rather than on neighbouring trees, therefore decreasing the amount of the reflective sunlit background visible which is not intrinsically related with the optical property of vegetation. An increasing NIR canopy reflectance at larger LAI and canopy cover is attributed to more sunlit and shaded canopy contributing to the canopy reflectance. Likewise, as the LAI and canopy closure increase, the red reflectance decreases as less of the reflective sunlit background is observed. Fig. 5 shows also the reflective property of SWIR which is not consistent with LAI curves on various soil backgrounds. These assertions and the drawbacks of using single SVI for
LAI mapping are supported also by Brown et al. (2000) and Nemani et al. (1993).

RISR, however, overcomes the perturbing effect of the soil reflectance variations on LAI estimation whilst using the advantage of the three bands and thus recommended for further testing using new field datasets. The main reason for the obtained performance of RISR compared to the comparable SVI from the three spectral bands (RSR) is that the SWIR correction of SR resulting in RSR is strongly influenced by the SWIR response to the landscape moisture. This response can have contrasting trend as shown in Fig. 5 for various soil moisture contents. On other hand, the red correction of ISR resulting in RISR is less affected by the soil moisture, because the red response always show consistent decreasing trend for increasing LAI and soil moisture (Fig. 5). Since the ISR already captures the changing LAI consistently, the correction of it using the red reflectance further eliminates the influence of the soil background. The applicability of the RISR needs further validation with more ground measurements representing large dynamic ranges of LAI and soil background.

Based on the SVI-LAI sensitivity functions, several SVIs can be used for mapping LAI by scaling back all SVIs to the same level. Other promising approach is the use of the normalized sensitivity function which does not require the a priori normalization of SVIs 

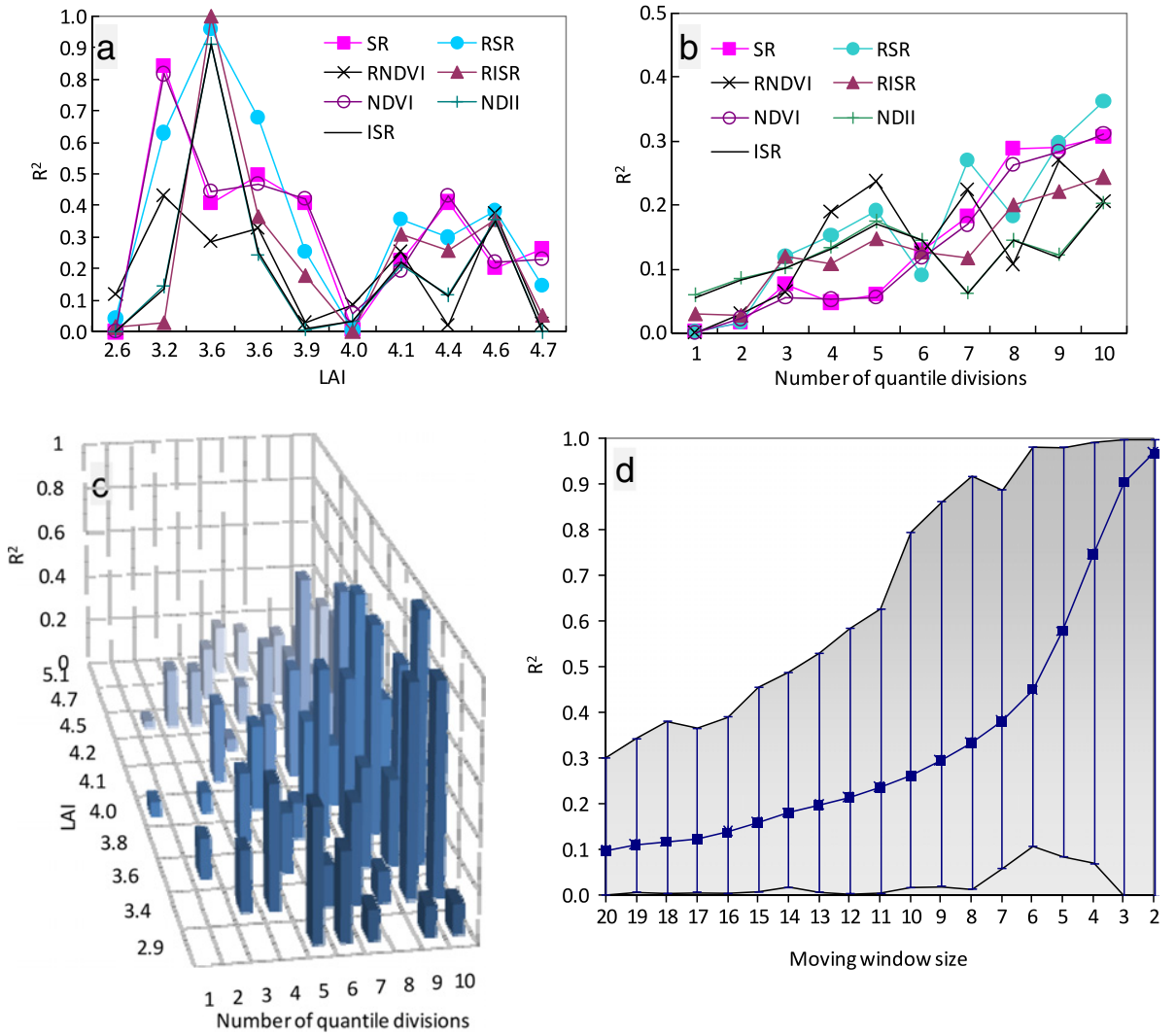

Fig. 11. The sensitivity assessment of SVIs for LAI estimation using localized correlation analysis. (a) The $R^{2}$ of SVI-LAI relationship computed for each of the 10 quantile divisions plotted along the average LAI of each quantile, (b) the average $R^{2}$ of SVI-LAI relationship computed for varying numbers of quantile divisions, (c) the $R^{2}$ of the best-fit SVI-LAI relationship computed for varying numbers of quantile divisions, and (d) the $R^{2}$ of the best-fit SVI-LAI relationship with varying moving window sizes (the error bars and gray shades indicate the minimum and maximum whereas the solid scatter line indicates the average value). The window size indicates the number of individual cases. The formulations of the indices are given in Table 1

to the same scale (Gonsamo, 2011). For operational product, this can be achieved by evaluating the SVI-LAI relationships for each land cover to select the SVI which is suitable for that specific land cover type. The use of various SVIs for LAI mapping from remotely sensed optical observations has been successfully applied for production of GLOBCARBON LAI time series (Deng et al., 2006). The new SVI and the sensitivity methodologies shown in this study will be indispensable to further explore the use of multiple SVIs for LAI mapping in heterogeneous landscapes.

\section{Conclusions}

In this paper, two datasets are used in order to demonstrate the use of SVI-LAI sensitivity analysis and subsequently applying for LAI mapping. Analysis with PROSAIL simulation datasets illustrated the varying sensitivity of seven SVIs used in this study at various LAI ranges. The simulated datasets further indicated that several SVIs can be used for LAI mapping provided that the $S$ function results are sufficiently large enough. It was also further demonstrated that, even if $S$ is statistically significant to show SVI sensitivity to LAI, it does not necessarily indicate that the relationship obtained from the $S$ function can be used for LAI mapping. This was the case of the real dataset in this study where the relationships which resulted in statistically significant $S$ resulted in statistically insignificant relationships when applied for LAI mapping.

One of the most intriguing results is the ability of the newly developed index called RISR to reduce varying soil background reflectance effect for potential LAI retrieval. Our major objectives were to test the $S$ function on the simulated dataset and to evaluate the applicability of the sensitivity assessment for further mapping the LAI using the real dataset, rather than provide a comprehensive comparison of SVIs. However, we have also shown the relationships of each spectral bands, soil effect, and sensitivity assessment using classical regression functions. Further study is required to apply the sensitivity analysis aiming at mapping LAI based on remotely sensed data and a wide range of ground based measurements on varying soil conditions. Whether the sensitivity functions hold the same for the datasets obtained from multiple dates is a further research question to be addressed as well.

\section{Acknowledgments}

The research was funded by the Academy of Finland through the TAITATOO-project and personal grant to Petri Pellikka, and by Natural Sciences and Engineering Research Council of Canada funding to Douglas King. The SPOT image was obtained from OASIS program financed by the European Commission, DG Research. The first author is financed partly by CIMO, Department of Geography of University of Helsinki, and the Finnish Graduate School of Geography. We are grateful to constructive suggestions provided by three anonymous reviewers.

\section{References}

Baret, F., Guyot, G., 1991. Potentials and limits of vegetation indices for LAI and APAR assessment. Remote Sensing of Environment 35 (2-3), 161-173.

Baret, F., Guyot, G., Begue, A., Maurel, P., Podaire, A., 1988. Complementarity of middle infrared with visible and near-infrared reflectance for monitoring wheat canopies. Remote Sensing of Environment 26 (3), 213-225. 
Becker, F., Choudhury, B.J., 1988. Relative sensitivity of normalized difference vegetation index (NDVI) and microwave polarization difference index (MPDI) for vegetation and desertification monitoring. Remote Sensing of Environment 24 (2), 297-311.

Bowker, D.E., Davis, R.E., Myrick, D.L., Stacy, K., Jones, W.T., 1985. Spectral reflectances of natural targets for use in remote sensing studies. NASA Reference Publication 1139, 1-188.

Brown, L., Chen, J.M., Leblanc, S.G., Cihlar, J., 2000. A shortwave infrared modification to the simple ratio for LAI retrieval in boreal forests: an image and model analysis. Remote Sensing of Environment 71 (1), 16-25.

Carlson, T.N., Ripley, D.A., 1997. On the relation between NDVI, fractional vegetation cover, and leaf area index. Remote Sensing of Environment 62 (3), 241-252.

Chen, J.M., Pavlic, G., Brown, L., Cihlar, J., Leblanc, S.G., White, H.P., Hall, R.J., Peddle, D.R., King, D.J., Trofymow, J.A., Swift, E., Van der Sanden, J., Pellikka, P.K.E., 2002. Derivation and validation of Canada-wide coarse-resolution leaf area index maps using high resolution satellite imagery and ground measurement. Remote Sensing of Environment 80 (1), 165-184.

Cohen, W.B., Maiersperger, T.K., Gower, S.T., Turner, D.P., 2003. An improved strategy for regression of biophysical variables and Landsat ETM+ data. Remote Sensing of Environment 84 (4), 561-571.

Deng, F., Chen, J.M., Plummer, S., Chen, M., Pisek, J., 2006. Algorithm for global leaf area index retrieval using satellite imagery. IEEE Transactions on Geoscience and Remote Sensing 44 (8), 2219-2229.

Fernandes, R., Butson, C., Leblanc, S., Latifovic, R., 2003. Landsat-5 TM and Landsat-7 ETM+ based accuracy assessment of leaf area index products for Canada derived from SPOT-4 VEGETATION data. Canadian Journal of Remote Sensing 29 (2), $241-258$.

Gitelson, A.A., 2004. Wide dynamic range vegetation index for remote quantification of biophysical characteristics of vegetation. Journal of Plant Physiology 161 (2), 165-173.

Gonsamo, A., 2010. Leaf area index retrieval using gap fractions obtained from high resolution satellite data: comparisons of approaches, scales and atmospheric effects. International Journal of Applied Earth Observation and Geoinformation $12(4), 233-248$.

Gonsamo, A., 2011. Normalized sensitivity measures for leaf area index estimation using three-band spectral vegetation indices. International Journal of Remote Sensing 32 (7), 2069-2080.

Gonsamo, A., Pellikka, P., 2008. Methodology comparison for slope correction in canopy leaf area index estimation using hemispherical photography. Forest Ecology and Management 256 (4), 749-759.

Gonsamo, A., Pellikka, P., King, D.J., 2011. Large scale leaf area index inversion algorithms from high resolution airborne imagery. International Journal of Remote Sensing 32 (14), 3897-3916.
Gower, S.T., Norman, J.M., 1991. Rapid estimation of leaf area index in conifer and broad-leaf plantations. Ecology 72 (5), 1896-1900.

Hardisky, M.A., Klemas, V., Smart, R.M., 1983. The influences of soil salinity, growth form, and leaf moisture on the spectral reflectance of Spartina alterniflora canopies. Photogrammetric Engineering and Remote Sensing 49 (1), 77-83.

Huete, A., Justice, C., Liu, H., 1994. Development of vegetation and soil indices for MODIS-EOS. Remote Sensing of Environment 49 (3), 224-234.

Jacquemoud, S., Baret, F., 1990. PROSPECT: a model of leaf optical properties spectra. Remote Sensing of Environment 34 (2), 75-91.

Ji, L., Peters, A.J., 2007. Performance evaluation of spectral vegetation indices using a statistical sensitivity function. Remote Sensing of Environment 106 (1), 59-65.

Jordan, C.F., 1969. Derivation of leaf area index from quality of light on the forest floor. Ecology 50 (4), 663-666.

Kalácska, M., Sánchez-Azofeifa, G.A., Rivard, B., Calvo-Alvarado, J.C., Journet, A.R.P., Arroyo-Mora, J.P., Ortiz-Ortiz, D., 2004. Leaf area index measurements in a tropical moist forest: a case study from Costa Rica. Remote Sensing of Environment 91 (2), 134-152.

Nemani, R.R., Pierce, L.L., Running, S.W., Band, L., 1993. Forest ecosystem processes at the watershed scale: sensitivity to remotely-sensed leaf area index estimates. International Journal of Remote Sensing 14 (13), 2519-2534.

Pellikka, P., Seed, E.D., King, D.J., 2000. Modelling deciduous forest ice storm damage using aerial cir imagery and hemispheric photography. Canadian Journal of Remote Sensing 26 (5), 394-405.

Rouse, J.W., Haas, R.H., Schell, J.A., Deering, D.W., 1974. Monitoring vegetation systems in the Great Plains with ERTS. In: Freden, S.C., Mercanti, E.P., Margaret A., Becker, M.A. (Eds.), Proceedings of the Third Earth Resources Technology Satellite-1 ERTS Symposium, NASA SP-351, vol. I, pp. 301-319.

Running, S., Baldocchi, D., Turner, D., Gower, S., Bakwin, P., Hibbard, K., 1999. A global terrestrial monitoring network integrating tower fluxes, flask sampling, ecosystem modeling and EOS data. Remote Sensing of Environment 70 (1), 108127.

Schabenberger, O., Pierce, F.J., 2002. Contemporary Statistical Models for the Plant and Soil Sciences. CRC Press, Boca Raton, FL.

Verhoef, W., 1984. Light scattering by leaf layers with application to canopy reflectance modelling: the SAIL model. Remote Sensing of Environment 16 (2), 125-141.

Vermote, E.F., Tanré, D., Deuzé, J.L., Herman, M., Morcrette, J.J., 1997. Second simulation of the satellite signal in the solar spectrum, 6S: an overview. IEEE Transactions on Geoscience and Remote Sensing 35 (3), 675-686.

Verstraete, M.M., Pinty, B., 1991. The potential contribution of satellite remote sensing to the understanding of arid lands processes. Vegetation 91 (1-2), 5972 . 